\title{
Are we training our novices towards quality 2D profiles for 3D models?
}

\author{
C. González-Lluch*, R. Plumed \\ Departament of Mechanical Engineering and Construction, Universitat Jaume I, Castellón 12071, \\ Spain \\ * Corresponding author: Tel.: +3-496-472-8123; fax: +3-496-472-8106; \\ E-mail address:mlluch@uji.es
}

\begin{abstract}
In the history-based, feature-based, parametric $\mathrm{CAD}$ approach, 2D profile sketches are the basis for 3D models. Fully-constraining profiles is mandatory to create robust profiles. At present, neither CAD applications nor Model Quality Testing Tools usually check whether $2 \mathrm{D}$ profiles contain redundant constraints. Besides, our experience shows that novices tend to introduce redundant constraints. We hypothesize that 2D profiles over-constrained with redundant relations are more difficult to edit than those that avoid redundancies. In the present work-and as a first step to demonstrate this hypothesis - an experiment was conducted. Students of the subject "Graphics engineering" were taught on the creation of constrained 2D profiles. Then, they were asked two questions. On the one hand, novices had to identify and reason whether a simple given profile was fully-constrained, over-constrained or under-constrained. On the other hand, they had to identify and point out the types of the constraints. The results showed that in spite that novices received a specific training, roughly half of them failed to say if the 2D profile sketch was fully-constrained and which type of constraints it contained. Furthermore, the results of the second question revealed that more than the half of students did not recognize perpendicularity as a geometric constraint. As future work, we will try to demonstrate whether a reinforced training through simple exercises and a quick and effective feedback, will allow novices to improve the identification and removal of redundant $2 \mathrm{D}$ constraints when drawing $2 \mathrm{D}$ profile sketches (thus helping to produce robust profiles).
\end{abstract}

Keywords: CAD model quality; 2D profile sketch; Fully-contrained profile; over-contrained profile; under-costrained profile. 


\section{Introduction}

Currently, 3D CAD models are an important issue in New Product Development (NPD) process. This fact has influenced the development of the CAD data quality field. "Product data" includes CAD (computer aided design) data, CAM (computer aided manufacturing), CAE (computer aided engineering) and PDM (product data management) among others. Poor data quality management compromises the benefits of historybased parametric feature based on mechanical CAD systems (MCAD), and specifically with the CAD model reuse.

High quality models are essential [1]. Contero et al. [1] proposed three levels of quality to classify CAD models: Morphologic, Syntactic and Semantic/pragmatic. The third level (Semantic/pragmatic), considers the CAD model capability for reusing and modification. Reusability and interoperability of a CAD model are the most typical tasks carried out during the product design process. Reusability of CAD models is an important issue to create high quality models. A model is reusable when it allows modifications while it maintains its design intent [2], and if it is simultaneously flexible (facilitate design alterations) and robust [3,4]. A robust model must allow for changes while must not produce unexpected failures. According to Jackson, et al. [5] up to 48\% of CAD models fail after a change is performed. A model is ineffective if its design intent is not maintained when the model is altered [2]. Generally understood, design intent is a CAD model's anticipated behavior when it is altered. Attending to ISO definition, design intent is the, "intentions of the designer of a model with regard to how it may be instantiated or modified" [6]. Models with high quality must reliable allow for modifications while maintaining their original design intent. In terms of training in CAD systems, very few studies have pay attention to students and how to create models which can be easily understood, altered and reused by others [7]. A recent study [8], addresses the reuse of 3D CAD models from the point of view of CAD learning and it takes into account the use of design intent during this learning.

A feature and history-based parametric CAD model builds models on top of 2D profiles - where geometric, dimensional and position constraints are introduced - using modeling operations, and through a model sequence (model tree). Otey et al. [9] present that sketch constraints join to "relationships between modeling operations" and "modeling operations" to embed the design intent in 3D CAD models. However, redundant restrictions don't provide additional information to the intent design. Quality of 2D profile is tightly related to its constraints. Ault et al. [10] showed that constraints can be applied to obtain flexible geometric models avoiding undesirable geometry or topology changes. According to González-Lluch et al. [2], the model is efficient if among other conditions, the design decisions are traceable within the model tree. As non-functional constraints, redundant constraints are inefficient and a type of "missing design intent" error in procedural models [2]. To obtain a robust and quality 2D profile, this must be necessary fully-constrained [11]. A common way to identify the quality of 2D profiles is to quantify their degrees of freedom. A profile which is not fully-constrained has at least one degree of freedom.

While editing the profile, some 3D CAD applications provides some useful training information to students. For example, in case of the CAD 3D SolidWorks ${ }^{\circledR}$ software, 
it is possible to detect whether a profile is fully constrained since it is been created by observing its line color, which can be configured from the program's configuration menu. Furthermore, a minus sign (-) preceding the profile name appears when the sketch is under constrained. Therefore, this history-based parametric CAD application provides information to user about under and over-constrained profile sketches. However, it should be pointed out that in case of over constrained profile with redundant relations, i.e. repetitive but not incompatible, the application does not provide any warning.

We classify constraints as: dimensional, constraints that associate geometric entities to each other (coincident, concentric, collinear, parallel, perpendicular, tangent, smooth, symmetric, equal, etc...), position and orientation constraints.

Our experience in teaching novices is that students tend to introduce redundant constraints when 2D profile sketches are created in a 3D model. Users can receive help from user's manuals and Model Quality Testing tools (MQT). Although, as it was shown in a recent study [12] - which examined a representative commercial MQT - these tools provide limited testing and tutoring capabilities. Therefore, we strongly believe that a correct training of novices and a quick feedback are essential for learning. As some researches of the literature show, educators have worked in the incorporation of activities which introduce product data quality concepts like the assessment of CAD models through the development of rubrics [11], [13], and the increase of students' awareness of methodological aspects of CAD model construction using activities or specific exercises [8], $[14,15,16]$. Some studies have shown that an early feedback is essential to improve their modeling strategies [17]. In addition, this feedback should be continuous in a formative sense [18].

Our hypothesis is that $2 \mathrm{D}$ profiles over-constrained with redundant relations are more difficult to edit than those that avoid redundancies. In a related study, GonzálezLluch et al. [19] demonstrated that the use of fix constraints (a typical case of a low semantic level constraints) compromises the reusability of the 3D model. Our experience like CAD instructors is that students tend to use redundant relations while creating $2 \mathrm{D}$ profiles. We consider that this type of relation prevents easy reuse of CAD models.

To demonstrate the hypothesis that " $2 \mathrm{D}$ profiles (in $3 \mathrm{D}$ models) that contain overconstrained with redundant relations are more difficult to edit than those that are fully constrained, even if they use low semantic constraints", it is necessary to follow several steps. In this work, we present the first step, which consists in conducting an experiment to know if students are capable of: (1) identifying fully-constrained profiles by an example, and (2) if they are able to detect (on the same example) dimensional, geometric, position and orientation constraints. Results show (in spite of students' training) that more than half of the polled students did not give a correct answer.

\section{Experiment}

One of the learning outcomes of the subject "Graphics engineering" (third course of "Bachelor's Degree in Mechanical Engineering" at Jaume I University) is that students 
have to apply computer-aided three-dimensional modeling (3D CAD) for the resolution of graphic engineering problems. Throughout the course, students attend both theory and practical classes.

In the beginning of the course, students are introduced to the creation of $2 \mathrm{D}$ profiles following the first chapter of [20]. On the one hand, during theory classes, students receive knowledge about constraints. In addition, they learn to distinguish the differences between over-constrained and under-constrained profiles. On the other hand, during lab hours, students are introduced to the use of a 3D CAD application (SolidWorks $\left.{ }^{\circledR}\right)$ and specific rubrics to convey quality criteria in Mechanical CAD Systems (assertions maps can be consulted in [11]).

Students are trained to create robust and flexible profiles through easy and simple examples (Figure 1). To this end, profiles are defined using geometric, dimensional, position and orientation constraints. In order to check the correctness of the constraining process, some changes are proposed on the profiles by editing the figures. The objective is to detect if these changes are allowed and if they result in the new expected profiles, or on the contrary, profiles fail to be recalculated by the CAD application.
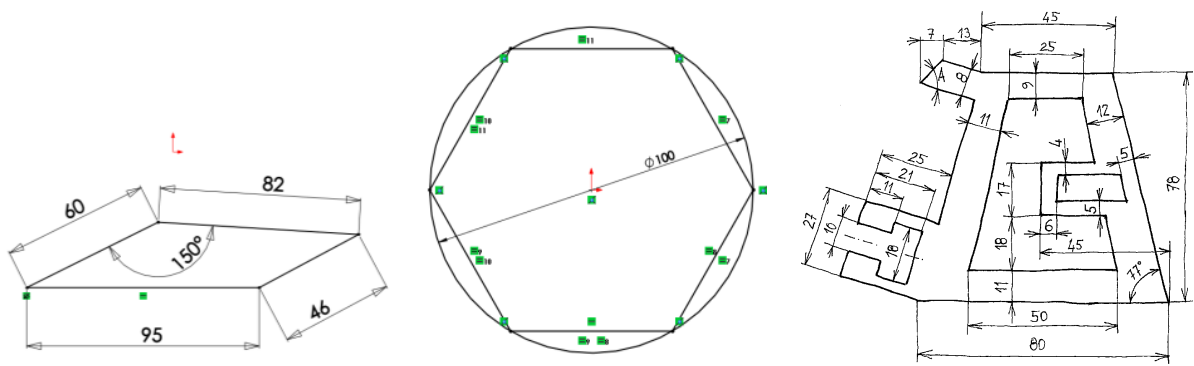

Fig 1. Profiles created during the first two sessions by students following teachers' guide

In the first midterm exam of the 2017/2018 course, students who coursed this subject had to solve two questions related with constraints. In the first question, students were asked if the profile showed in Figure 2 was fully-constrained, over-constrained or under-constrained. The answer had to be reasoned.

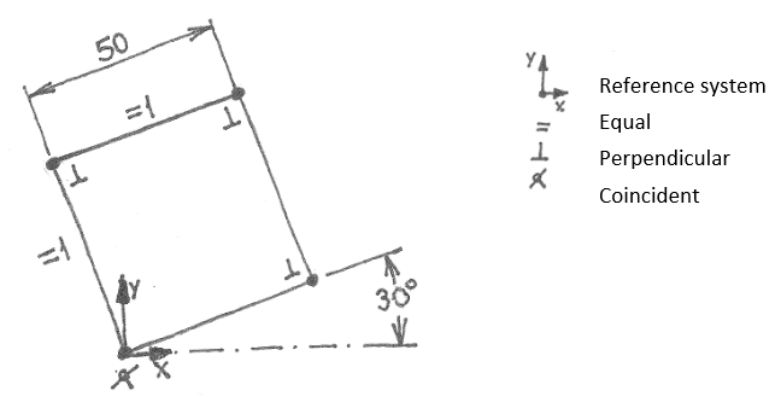

Fig 2. First question of midterm of "Graphics engineering". 
The correct answer, to this first question, is that this 2D profile is fully-constrained. This answer is easily testable to a 3D CAD application (for example Solidworks ${ }^{\circledR}$ ).

In the second question, the same figure 2 was presented. In this case, students had to identify and point out each type of the constraint. The types of constraints that they were asked to distinguish were: dimensional or geometric $(\mathrm{F})$, position and orientation (P) and the rest (B). In addition, they had to argue their answer.

Considering the discretionary margin of the solution, we consider that this $2 \mathrm{D}$ profile include these constraints:

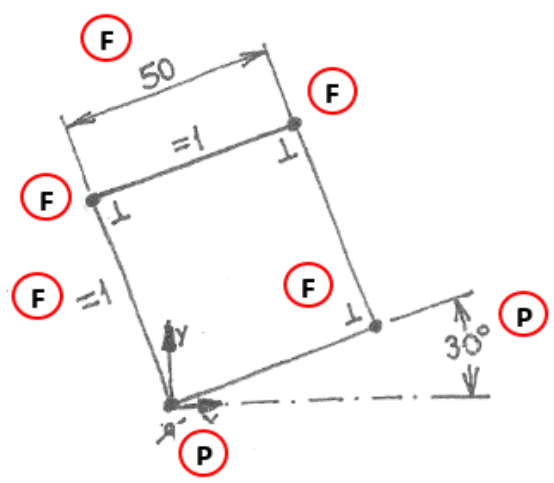

Fig 3. Considered constraints of the $2 \mathrm{D}$ profile proposed in the first question.

In the case of the angular restriction $\left(30^{\circ}\right)$, another alternative could be to consider it as dimensional or geometric (F). Instead, we consider this angular restriction as an orientation constraint, because it associates the geometry of the profile with the reference system.

\section{Results of the experiment}

A total of 34 answers were collected from the students and considered to the study. All the students answered both questions.

The percentage of students that successfully answered question 1 (fully constrained profile) is shown in Table 1.

Table 1. Data summary from the A question.

\begin{tabular}{llll}
\hline Question A: & "Fully constrained" & "Over constrained" & "Under constrained" \\
\hline (\%) students & $47.1 \%$ & $50 \%$ & $2.9 \%$ \\
Total of students & 16 & 17 & 1 \\
\hline
\end{tabular}

Table 2, shows the percentage of students that successfully answered question 2 . In case of incorrect answer, detailed information/failure description is showed in Table 3. 
Table 2. Data summary from the B question.

\begin{tabular}{llll}
\hline Question B: & & Correct answer & Incorrect answer \\
\hline$\%$ & $47.1 \%$ & $52.9 \%$ \\
Total of students & 16 & 18 \\
\hline
\end{tabular}

Table 3. Additional information from incorrect answers from B question.

\begin{tabular}{|c|c|c|c|}
\hline Student answer & $\%$ Students & $\begin{array}{l}\text { Total of } \\
\text { students }\end{array}$ & Additional information \\
\hline \multirow{3}{*}{$\begin{array}{l}\text { All perpendicular con- } \\
\text { straints }\end{array}$} & \multirow[t]{3}{*}{$87.4 \%$} & \multirow[t]{3}{*}{14} & From this result: \\
\hline & & & $\begin{array}{l}11 \text { students, pointed that perpendicular con- } \\
\text { straints are of type } P\end{array}$ \\
\hline & & & $\begin{array}{l}3 \text { students pointed that perpendicular con- } \\
\text { straints are of type B }\end{array}$ \\
\hline $\begin{array}{l}2 \text { incorrect perpendicular } \\
\text { constraints }\end{array}$ & $6.25 \%$ & 1 & $\begin{array}{l}\text { The student pointed that } 2 \text { perpendicular con- } \\
\text { straints are of type } B\end{array}$ \\
\hline $\begin{array}{l}1 \text { incorrect perpendicular } \\
\text { constraints }\end{array}$ & $6.25 \%$ & 1 & $\begin{array}{l}\text { The student pointed that } 1 \text { perpendicular con- } \\
\text { straint is of type B }\end{array}$ \\
\hline Equal constraints & $18.75 \%$ & 3 & $\begin{array}{l}\text { The students pointed that the equal con- } \\
\text { straints are of type B }\end{array}$ \\
\hline Dimension constraints & $12.5 \%$ & 2 & $\begin{array}{l}\text { The students don't point one of the dimen- } \\
\text { sions }\end{array}$ \\
\hline
\end{tabular}

The results showed that despite students had received specific training with theoretical and practical classes, more than a half of them (52.9\%) did not distinguish if the simple 2D profile was fully constrained.

In reference to the results from the second questions, the results show that more than half of participants failed to differentiate between dimensional/geometric and position/orientation constraints. Results from question B (Table 3) show that most of students who had failed the question $(87.4 \%)$, did not recognized the perpendicular constraints as a geometric restriction, as the majority of students considered these constraints as type $\mathrm{P}$ (position and orientation) and $\mathrm{B}$ (the rest).

\section{Conclusions}

In current work, we present a study to prove if we are training our novices towards quality $2 \mathrm{D}$ profiles for $3 \mathrm{D}$ models. At this end, we have conducted a pilot experiment which shows that students fail to recognize the different types of constraints in the examples proposed. This fact, suggests that students are unlikely to use constraints in a robust and efficient way to avoid redundant constraints. They are also unlikely to choose the more representative constraints to convey the design intent. Our experience 
shows us that novices tend to introduce redundant constraints even in simple profile sketches, although they have received a specific training and a limited assistance by CAD 3D system.

The results of the experiment showed that half of students could not identify a fullyconstrained profile neither the type of constraints that contained. Therefore, we conclude that an improvement of the knowledge of novices is necessary as a previous step to obtain profiles with less redundant constraints. Hence, our natural next step is the preparation of a tool that provides knowledge and early feedback to obtain profiles with less redundant constraints to facilitate the edition of 2D profiles, in 3D CAD models.

\section{Acknowledgments}

This is a pre-copyredited version of a contribution published in: Cavas-Martínez F., Eynard B., Fernández Cañavate F., Fernández-Pacheco D., Morer P., Nigrelli V. (eds) Advances on Mechanics, Design Engineering and Manufacturing II published by Lecture Notes in Mechanical Engineering. Springer. The definitive authenticated version is available online via https://doi.org/10.1007/978-3-030-12346-8_69

\section{References}

1. Contero, M., Company, P., Vila, C., Aleixos, N.: Product data quality and collaborative engineering. IEEE Computer Graphics and Applications, 22 (3), 32-42 (2002).

2. González-Lluch, C., Company, P., Contero, M., Camba, J.D., Plumed, R.: A survey on 3D CAD model quality assurance and testing tools. Computer-Aided Design 83, 64-79 (2017).

3. Camba, J.D., Contero, M., Company, P.: Parametric CAD modeling: An analysis of strategies for design reusability. Computer-Aided Design, 74, 18-31 (2016).

4. Cheng, Z., Ma, Y.: A functional feature modeling method. Avanced Engineering Informatics, 33, 1-15 (2017).

5. Jackson, C.; Buxton, M.: The Design Reuse Benchmark Report, 1-20 (2017).

6. ISO 10303-55:2005 Industrial automation systems and integration - Product data representation and exchange - Part 55: Integrated generic resource: Procedural and hybrid representation, https://www.iso.org/obp/ui/\#iso:std:iso:10303:-55:ed-1:v1:en, last accessed 2018/02/22.

7. Peng, X., Mcgary, P., Johnson, M., Yalvac, B., Ozturk, E.: Assessing Novice CAD Model Creation and Alteration. Computer-Aided Design \& Applications, (2), 9-19 (2012).

8. Barbero, B.R., Pedrosa, C.M., Samperio, R.Z.: Learning CAD at university through summaries of the rules of design intent. International Journal of Technology and Design Education 27(3), 481-498 (2017).

9. Otey, J., Company, P., Contero, M., Camba, J.D.: Revisiting the design intent concept in the context of mechanical CAD education. Computer-Aided Design and Applications 15(1), 47-60 (2018). 
10. Ault, H.K.: Using Geometric Constraints to Capture Design Intent. Journal for Geometry and Graphics 3(1), 39-45 (1999).

11. Company, P., Contero, M., Otey, J., Plumed R.: Approach for developing coordinated rubrics to convey quality criteria in MCAD training. Computer-Aided Design 63, 101-117 (2015).

12. González-Lluch, C., Company, P., Contero, M., Camba J.D., Colom, J.: A Case Study on the Use of Model Quality Testing Tools for the Assessment of MCAD Models and Drawings. The International Journal of Engineering Education 33(5), 1643-1653 (2017).

13. Ault, H.K., Linjun, Bu.: Solid Modeling Strategies - Analyzing Student Choices. PROCEEDINGS OF THE 121ST ASEE ANNUAL CONFERENCE AND EXPOSITION. Indianapolis, June 15-18, Paper ID \#9242, n.d. (2014).

14. Branoff, T.J.: Constraint-Based Modeling in the Engineering Graphics Curriculum: Laboratory Activities and Evaluation Strategies. PROC. MIDYEAR CONF. ENG. DESIGN GRAPHICS DIVISION OF THE AM. SOC. FOR ENG. EDUCATION, Williamsburg, VA: p. 132-8. (2004).

15. Devine, K.L., Laingen M.A.: Assessing Design Intent in an Introductory-Level Engineering Graphics Course. 68TH MID-YEAR CONFERENCE. ASEE ENGINEERING DESIGN GRAPHICS DIVISION, Worcester:, p. 59-63. (2013).

16. Branoff, T., Wiebe, E., Hartman, N.: Integrating Constraint-Based CAD into an Introductory Engineering Graphics Course: Activities and Grading Strategies. PROCEEDINGS OF THE 2003 AMERICAN SOCIETY FOR ENGINEERING EDUCATION ANNUAL CONFERENCE \& EXPOSITION, AMERICAN SOCIETY FOR ENGINEERING EDUCATION; , p. Session 1338, 1-10. (2003).

17. Kirstukas, S.J.: Development and Evaluation of a Computer Program to Assess Student CAD Models. ASEE ANNUAL CONFERENCE \& EXPOSITION, paper ID15834, New Orleans, Lousiana:, p. 26-9. (2016).

18. Race, P.: The lecturer's toolkit : a practical guide to assessment, learning and teaching. Routledge-Falmer, Glasgow, Great Britain: (2015).

19. González-Lluch, C., Company, P., Contero, M., Pérez-López, D., Camba, J.D.: On the effects of the fix geometric constraint in 2D profiles on the reusability of parametric 3D CAD models (under review).

20. Company, P., González-Lluch, C.: CAD 3D con SolidWorks ${ }^{\circledR}$ Tomo I: Diseño básico. Publicacions Universitat Jaume I, Castellón (2013). 